\title{
Vazoactive Effects of Oxidative Stress Elicited by Hydrogen Peroxide in the Human Umbilical Artery: An in Vitro Study
}

\author{
Ipek Duman*, Necdet Dogan
}

Department of Pharmacology, Meram Faculty of Medicine, Selcuk University, Konya, Turkey.

Email: *ipekduman@yahoo.com

Received June $5^{\text {th }}, 2011$; revised July $20^{\text {th }}, 2011$; accepted August $30^{\text {th }}, 2011$.

\begin{abstract}
The vasoactive effects of oxidative stress induced by hydrogen peroxide $\left(\mathrm{H}_{2} \mathrm{O}_{2}\right)$ on human umbilical artery strips as well as the possible mechanisms involved are studied. Contraction responses to cumulative $\mathrm{H}_{2} \mathrm{O}_{2}\left(10^{-7} \mathrm{M}-3 \times 10^{-2} \mathrm{M}\right)$ in endothelium intact and denuded umbilical arteries and responses to cumulative $\mathrm{H}_{2} \mathrm{O}_{2}$ after incubation with L-NAME $\left(10^{-4} M\right)(n=8)$, indomethacin $\left(10^{-5} M\right)(n=8)$ and verapamil $\left(10^{-6}\right)(n=8)$ were recorded. Responses elicited with cumulative $\mathrm{H}_{2} \mathrm{O}_{2}$ in $\mathrm{Ca}^{2+}$ free extracellular medium and the responses to cumulative $\mathrm{Ca}^{2+}\left(10^{-4} \mathrm{M}-2 \times 10^{-3} \mathrm{M}\right)$ after $\mathrm{H}_{2} \mathrm{O}_{2}\left(10^{-3} \mathrm{M}\right)$ induced contraction were also studied. The $E_{\max }$ for each experiment was calculated. $p<0.05$ was considered as significant. $\mathrm{H}_{2} \mathrm{O}_{2}$ elicited contraction was greater in endothelium denuded artery strips compared to endothelium intact strips $(p<0.05)$. Compared to control, incubation with L-NAME significantly augmented $(p<0.05)$, while verapamil and indomethacin inhibited the contractions elicited by cumulative $\mathrm{H}_{2} \mathrm{O}_{2}(p<0.05)$. $\mathrm{Ca}^{2+}$ free extracellular medium caused decreases in cumulative $\mathrm{H}_{2} \mathrm{O}_{2}$ elicited contractions and cumulative $\mathrm{Ca}^{2+}$ caused concentration dependent increases in the contraction caused by a single bolus of $\mathrm{H}_{2} \mathrm{O}_{2}(p<0.05)$. Exposure to $\mathrm{H}_{2} \mathrm{O}_{2}$ causes concentration-dependent constriction in human umbilical arteries. The presence of the endothelium and NOS enzyme activation influences the $\mathrm{H}_{2} \mathrm{O}_{2}$ responses. Removal of the endothelium increases the $\mathrm{H}_{2} \mathrm{O}_{2}$ elicited contractions more than incubation with L-NAME suggesting beside NO, other endothelial vasodilators are also involved in vascular tonus of the umbilical arteries. Both intracellular and extracellular $\mathrm{Ca}^{2+}$ ions and constrictor cyclooxygenase metabolites play a role in the contractile responses elicited by $\mathrm{H}_{2} \mathrm{O}_{2}$ in human umbilical arteries.
\end{abstract}

Keywords: Umbilical Arteries, Hydrogen Peroxide, Indomethacin, L-NAME, Oxidative Stress, Pre-Eclampsia, Reactive Oxygen Species, Verapamil

\section{Introduction}

Pre-eclampsia (PE) is a major cause of fetal growth restriction and perinatal complications. In PE, there is increased resistance to placental circulation which leads to reduced uteroplacental blood flow followed by placental dysfunction and intrauterine fetal growth restriction [1,2]. Umbilical blood vessels are not innervated therefore the control of umbilical blood flow depends entirely on vasoreactive substances either released locally or presented in the circulation [3]. Pregnancy is a state of oxidative stress, characterized by the placental production of reactive oxygen species (ROS) including superoxide and hydrogen peroxide $\left(\mathrm{H}_{2} \mathrm{O}_{2}\right)$ [4,5]. It is considered that during normal pregnancy, the rate of production of ROS is offset by their elimination by abundant antioxidant defenses. However in PE and preterm labor, due to excessive oxidative stress and lipid peroxidation (LPO) ROS overpowers antioxidant defenses, leading to reduction of uteroplacental blood flow $[5,6] \cdot \mathrm{H}_{2} \mathrm{O}_{2}$ is a powerful by product of LPO and is used as a model of oxidative stress. $\mathrm{H}_{2} \mathrm{O}_{2}$ easily crosses cell membranes and lead to cellular oxidative damage. LPO has been studied intensively over decades and remains to be a hot topic in biological research but still there is little information on the effects of LPO on human umbilical arteries [7-9]. This in vitro study was designed to assess the effects of $\mathrm{H}_{2} \mathrm{O}_{2}$ used as a model of oxidative stress on human umbilical arteries as well as the possible mechanisms involved. 


\section{Materials and Methods}

The University Human Ethics Committee approved this study. All umbilical cords used in the experiments were remnant tissues, which would have otherwise been discarded.

\subsection{Sample Collection}

After maternal consent, human umbilical cords were collected from healthy full-term normal deliveries. After delivery, the umbilical cord was clamped at both placental and fetal ends. An untouched $15-20 \mathrm{~cm}$ long segment of the umbilical cord was taken from the placental side within 10 min of delivery and placed in cold KrebsHenseleit solution for transport to the laboratory.

\subsection{Blood Vessel Preparation}

Umbilical arteries were separated from the surroundings in warm modified Krebs-Henseleit solution. The isolated artery was cut spirally to form $2-3 \mathrm{~mm}$ wide and $15-20$ $\mathrm{mm}$ long strips. The strips were suspended between two stainless steel hooks in organ baths $(10 \mathrm{ml})$ containing Krebs-Henseleit buffer maintained at $37^{\circ} \mathrm{C}$. One hook was anchored onto the organ bath and the other was connected to a movable transducer (Model FT 03, Grass Instrument Co. MA, USA) and a polygraph (Model 7, Grass Instrument Co. MA, USA) for measurement and recording of changes in isometric tension.

\subsection{Experimental Protocols}

Protocols were conducted with endothelium intact artery strips except for protocol 1 which used both endothelium intact and endothelium denuded artery strips. Endothelium removal was done by gently denuding the endothelium of the artery with cotton swabs. The integrity of the endothelium was tested by, first pre-contracting the denuded strips with serotonin $\left(10^{-4} \mathrm{M}\right)$, and then adding acetylcholine $\left(10^{-6} \mathrm{M}\right)$ before each experiment. Removal of the endothelium was confirmed if the vessels contracted in response to acetylcholine.

Strips were aerated with a gas mixture of $95 \% \mathrm{O}_{2}: 5 \%$ $\mathrm{CO}_{2}$ throughout the experiment. Strips were initially placed under a resting tension of $1 \mathrm{~g}$ and were allowed to equilibrate for one hour. During this period the bath solution was changed every 15 minutes and the resting tension was readjusted to the $1 \mathrm{~g}$ level. Following the washout period, the initial control contraction of the strips to serotonin $\left(10^{-4} \mathrm{M}\right)$ was recorded. The strips were washed again with the buffer solution and allowed to rest. After an equilibrium period, the following procedures were conducted at $37^{\circ} \mathrm{C}$ :

Protocol 1: to determine the role of the endothelium on the reactivity of the human umbilical artery to $\mathrm{H}_{2} \mathrm{O}_{2}$, umbilical artery strips both with intact endothelium $(\mathrm{n}=$ $8)$ and denuded endothelium $(n=8)$ were used. The strips precontracted with serotonin $\left(10^{-4} \mathrm{M}\right)$ were subjected to cumulative doses of $\mathrm{H}_{2} \mathrm{O}_{2}\left(10^{-7} \mathrm{M}-3 \times 10^{-2} \mathrm{M}\right)$ at resting tension and concentration-response curves were obtained. Further protocols were conducted with endothelium intact artery strips.

Protocol 2: to determine the role of nitric oxide (NO) in the mechanism of $\mathrm{H}_{2} \mathrm{O}_{2}$ elicited contractions; umbilical artery strips precontracted with serotonin $\left(10^{-4} \mathrm{M}\right)$ were incubated for 20 minutes with a NO synthase inhibitor, $\mathrm{N}^{\omega}$-nitro-L-arginine methyl ester (L-NAME) $\left(10^{-4} \mathrm{M}\right)$ $(\mathrm{n}=8)$ After this incubation, concentration-response curves were obtained to cumulative $\mathrm{H}_{2} \mathrm{O}_{2}\left(10^{-7} \mathrm{M}-3 \times 10^{-2}\right.$ M).

Protocol 3: to determine the role of prostanoids in the mechanism of $\mathrm{H}_{2} \mathrm{O}_{2}$ elicited contractions; umbilical artery strips precontracted with serotonin $\left(10^{-4} \mathrm{M}\right)$ were incubated for 20 minutes with a cyclooxygenase inhibitor, indomethacin $\left(10^{-5} \mathrm{M}\right)(\mathrm{n}=8)$. After this incubation, concentration-response curves were obtained to cumulative $\mathrm{H}_{2} \mathrm{O}_{2}\left(10^{-7} \mathrm{M}-3 \times 10^{-2} \mathrm{M}\right)$.

Protocol 4: to determine the role of $\mathrm{Ca}^{2+}$ channels in the mechanism of $\mathrm{H}_{2} \mathrm{O}_{2}$ elicited contractions; umbilicalk artery strips precontracted with serotonin $\left(10^{-4} \mathrm{M}\right)$ were incubated for 20 minutes with a $\mathrm{Ca}^{2+}$ channel blocker, verapamil $\left(10^{-6} \mathrm{M}\right)(\mathrm{n}=8)$. After this incubation, concentration-response curves were obtained to cumulative $\mathrm{H}_{2} \mathrm{O}_{2}\left(10^{-7} \mathrm{M}-3 \times 10^{-2} \mathrm{M}\right)$.

Protocol 5: the effects of $\mathrm{Ca}^{2+}$ on $\mathrm{H}_{2} \mathrm{O}_{2}$ elicited responses were studied in another group of umbilical arteries $(\mathrm{n}=8)$. The artery strips were allowed to rest in modified $\mathrm{Ca}^{2+}$ free Krebs-Henseleit solution containing $1 \mathrm{mM}$ of ethyleneglycol-bis-( $\beta$-aminoethyl ether) N'tetraacetic acid (EGTA) for $60 \mathrm{~min}$, which was changed every 15 min. Cumulative $\mathrm{H}_{2} \mathrm{O}_{2}\left(10^{-7} \mathrm{M}-3 \times 10^{-2} \mathrm{M}\right)$ was added to the organ bath and concentration-response curves were obtained. In a different group of umbilical strips $(n=8)$, the strips were allowed to rest in modified $\mathrm{Ca}^{2+}$ free Krebs-Henseleit solution containing $1 \mathrm{mM}$ of EGTA for $60 \mathrm{~min}$, which was changed every $15 \mathrm{~min}$. After obtaining a contraction curve with a bolus of $\mathrm{H}_{2} \mathrm{O}_{2}\left(10^{-3} \mathrm{M}\right)$, cumulative $\mathrm{Ca}^{2+}\left(10^{-4} \mathrm{M}-2 \times 10^{-3} \mathrm{M}\right)$ was added to the organ bath and concentration-response curves were obtained.

\subsection{Materials}

$\mathrm{H}_{2} \mathrm{O}_{2}$, magnesium sulphate $\left(\mathrm{MgSO}_{4}\right)$, potassium hydrogen phosphate $\left(\mathrm{KH}_{2} \mathrm{PO}_{4}\right)$ sodium bicarbonate $\left(\mathrm{NaHCO}_{3}\right)$, potassium chloride $(\mathrm{KCl})$, sodium chloride $(\mathrm{NaCl})$, and calcium chloride $\left(\mathrm{CaCl}_{2}\right)$ were obtained from Merck 
(Merck KGaA, Darmstadt, Germany) and serotonin hydrochloride, L-NAME, indomethacin, verapamil and EGTA were purchased from Sigma Chemical Co. (St. Louis, MO, U.S.A.). Krebs-Henseleit solution and modified Krebs-Henseleit without calcium were prepared in the laboratory with compositions of (in $\mathrm{mM}$ ) $\mathrm{NaCl} \mathrm{119}$; $\mathrm{KCl}$ 4.7; $\mathrm{MgSO}_{4} 1.5 ; \mathrm{KH}_{2} \mathrm{PO}_{4} 1.2 ; \mathrm{CaCl}_{2} 2.5 ; \mathrm{NaHCO}_{3}$ 25; glucose 11, and $\mathrm{NaCl} 119 ; \mathrm{KCl} 4.7 ; \mathrm{MgSO}_{4} 1.5$; $\mathrm{KH}_{2} \mathrm{PO}_{4} 1.2 ; \mathrm{NaHCO}_{3} 25$; glucose 11, EGTA 1 respectively. All agents were dissolved in distilled water.

\subsection{Data and Statistical Analysis}

The contraction is expressed as percentage (\%) of the contractile level that was induced by serotonin. The $\mathrm{E}_{\max }$ ( $\%$ of maximum contraction) in each group and $\mathrm{pD}_{2}$ (the negative logarithm of the concentration which elicits $50 \%$ contraction) for groups in which $\mathrm{E}_{\max }>50 \%$ were calculated. All results are expressed as the mean \pm standard deviation of mean and $\mathrm{n}$ denotes the number of human umbilical cords which the arterial strips were obtained. Analysis of variance (ANOVA) and Tukey's HSD tests were used were appropriate to determine the differences between the percentage values using a computer statistical package (SPSS, Chicago, IL, USA). p < 0.05 was considered as significant.

\section{Results}

\subsection{The Effect of Endothelium on $\mathrm{H}_{2} \mathrm{O}_{2}$ Elicited Contractions}

$\mathrm{H}_{2} \mathrm{O}_{2}\left(10^{-7} \mathrm{M}-3 \times 10^{-2} \mathrm{M}\right)$ elicited concentration dependent contraction in isolated human umbilical artery strips both with $\left(\mathrm{E}_{\max }=63.5 \pm 3.7, \mathrm{pD}_{2}=3.08 \pm 0.1\right)$ and without $\left(\mathrm{E}_{\max }=101.8 \pm 9.6, \mathrm{pD}_{2}=4.10 \pm 0.26\right)$ endothelium. There were significant differences among these strips in terms of $\mathrm{E}_{\max }$ and $\mathrm{pD}_{2}$ values with significantly larger contractions in the endothelium denuded strips ( $p$ $<0.05$ ) (Figure 1).

\subsection{The Effect of L-NAME, Indomethacin and Verapamil Incubation on $\mathrm{H}_{2} \mathrm{O}_{2}$ Elicited Contractions}

Compared to control $\left(\mathrm{E}_{\max }=63.5 \pm 3.7, \mathrm{pD}_{2}=3.08 \pm\right.$ $0.0)$, incubation with L-NAME significantly augmented $\left(\mathrm{E}_{\max }=91.8 \pm 8.3, \mathrm{pD}_{2}=3.74 \pm 0.2\right)(\mathrm{p}<0.05)$, while verapamil $\left(\mathrm{E}_{\max }=25.1 \pm 3.3\right)$ and indomethacin $\left(\mathrm{E}_{\max }=\right.$ $14.1 \pm 3.4)$ significantly inhibited the contractions elicited by cumulative $\mathrm{H}_{2} \mathrm{O}_{2}(\mathrm{p}<0.05)$ (Figure 2).

\subsection{The Effect of $\mathrm{Ca}^{2+}$ on $\mathrm{H}_{2} \mathrm{O}_{2}$ Elicited Contractions}

When compared with the maximum contraction responses

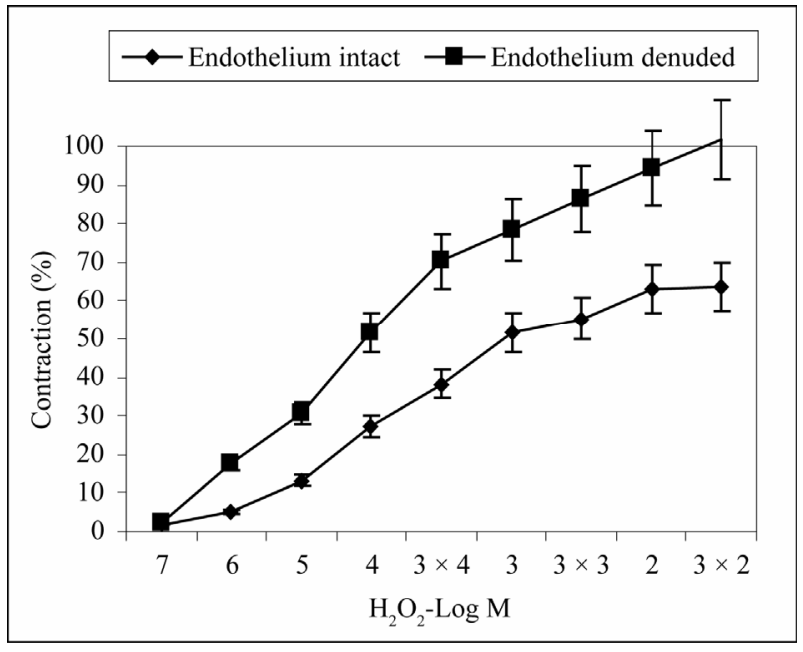

Figure 1. Concentration-response curves for cumulative $\mathrm{H}_{2} \mathrm{O}_{2}$ $\left(10^{-7} \mathrm{M}-3 \times 10^{-2} \mathrm{M}\right)$ on isolated human umbilical artery strips with and without endothelium. Data expressed as the percentage of the control contractile response elicited by $10^{-4}$ $M$ of serotonin. Mean \pm SD $(n=8)$.

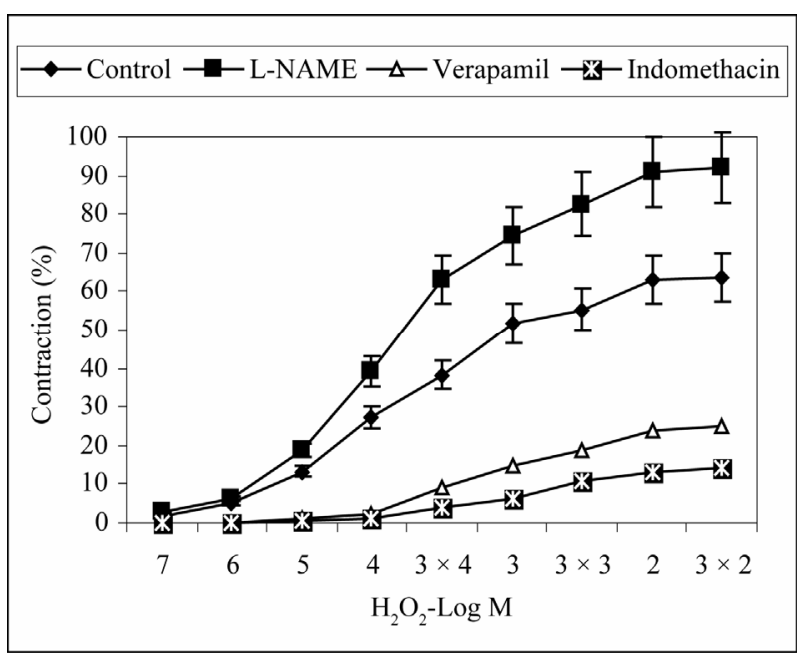

Figure 2. Concentration-response curves for cumulative $\mathrm{H}_{2} \mathrm{O}_{2}$ $\left(10^{-7} \mathrm{M}-3 \times 10^{-2} \mathrm{M}\right)$ on isolated human umbilical artery strips with endothelium after incubation with L-NAME $\left(10^{-4}\right.$ $\mathrm{M})$, verapamil $\left(10^{-6} \mathrm{M}\right)$ and indomethacin $\left(10^{-5} \mathrm{M}\right)$. Data expressed as the percentage of the control contractile response elicited by $10^{-4} \mathrm{M}$ of serotonin. Mean \pm SD $(n=8)$.

with Krebs-Henseleit solution $\left(\mathrm{E}_{\max }=63.5 \pm 3.7, \mathrm{pD}_{2}=\right.$ $3.08 \pm 0.0$ ), providing a $\mathrm{Ca}^{2+}$ free extracellular medium caused significant decreases in cumulative $\mathrm{H}_{2} \mathrm{O}_{2}$ elicited contractions $\left(\mathrm{E}_{\max }=38.7 \pm 5.8\right)(\mathrm{p}<0.05)$ (Figure 3). After resting in modified $\mathrm{Ca}^{2+}$ free Krebs-Henseleit solution, cumulative $\mathrm{Ca}^{2+}\left(10^{-4} \mathrm{M}-2 \times 10^{-3} \mathrm{M}\right)$ caused significant concentration dependent increases $\left(\mathrm{E}_{\max }=98.5 \pm\right.$ $6.1)$ in the contraction caused by a single bolus of $\mathrm{H}_{2} \mathrm{O}_{2}$ $\left(\mathrm{E}_{\max }=23.3 \pm 3.3\right)(\mathrm{p}<0.05)($ Figure 4). 


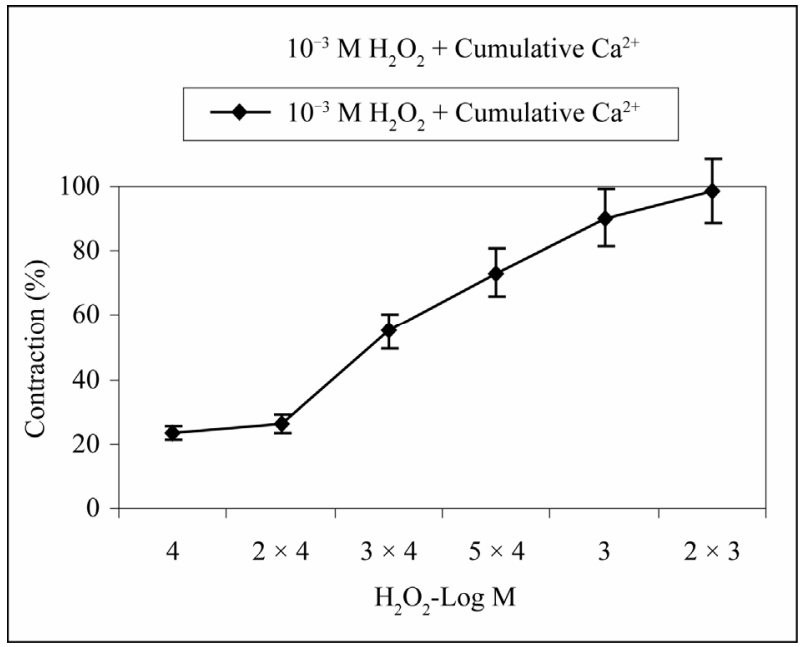

Figure 3. Concentration-response curves for cumulative $\mathrm{Ca}^{2+}\left(10^{-4} \mathrm{M}-2 \times 10^{-3} \mathrm{M}\right)$ on $\mathrm{H}_{2} \mathrm{O}_{2}\left(10^{-3} \mathrm{M}\right)$ induced constriction of human umbilical arteries. Data expressed as the percentage of the control contractile response elicited by $10^{-4} M$ of serotonin. Mean \pm SD $(n=8)$.

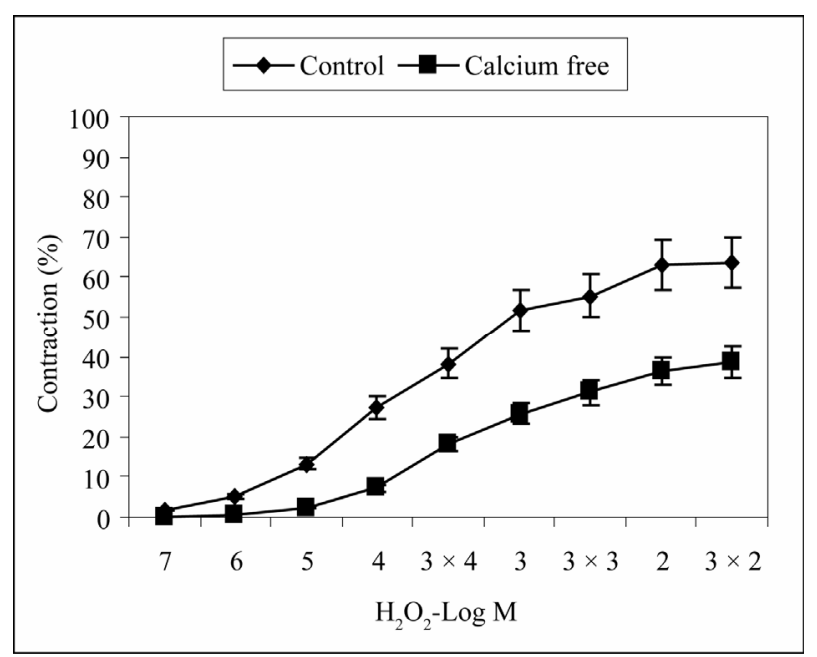

Figure 4. Concentration-response curves for cumulative $\mathrm{H}_{2} \mathrm{O}_{2}\left(10^{-7} \mathrm{M}-3 \times 10^{-2} \mathrm{M}\right)$ on isolated human umbilical artery strips in Krebs-Henseleit solution and modified KrebsHenseleit without calcium. Data expressed as the percentage of the control contractile response elicited by $10^{-4} \mathrm{M}$ of serotonin. Mean \pm SD $(n=8)$.

\section{Discussion}

The present study demonstrates that in vitro experimental model of oxidative stress elicited by $\mathrm{H}_{2} \mathrm{O}_{2}$ causes concentration dependent vasoconstriction in human umbilical arteries both with and without endothelium. Both intracellular and extracellular $\mathrm{Ca}^{2+}$ ions and cyclooxygenase enzyme activation play a role in the contractile responses elicited by $\mathrm{H}_{2} \mathrm{O}_{2}$ in human umbilical arteries.
The presence of the endothelium and NOS enzyme activation influences the $\mathrm{H}_{2} \mathrm{O}_{2}$ responses.

The known vasoactive substances responsible for the control of umbilical flow include local vasoconstrictors such as endothelin-1, thromboxane A2 and prostaglandin F2 $\alpha$ and also vasodilators such as prostacyclin (PGI2), nitric oxide (NO) and end8othelium derived hyperpolarizing factor (EDHF) [10,11]. It is known that under oxidative stress conditions such as pre-eclampsia placental vascular resistance increases [12,13]. The mechanisms by which ROS cause vasoconstriction are incompletely understood. At a vascular level, endothelial cells are a target for, and a source of, $\mathrm{H}_{2} \mathrm{O}_{2}$. Previous work with different species and vascular structures yielded conflicting results. Similar to our study, $\mathrm{H}_{2} \mathrm{O}_{2}$ caused vasoconstriction in human umbilical artery [14,15], pulmonary artery [16] and rat aorta [17]. Contrary to these results, $\mathrm{H}_{2} \mathrm{O}_{2}$ caused vasodilation in rabbit [18], rat mesenteric artery [19], guinea-pig aorta [20] and porcine coronary artery [21]. The above results lead us to think that the vasoactive properties of $\mathrm{H}_{2} \mathrm{O}_{2}$ vary with species, tissue and experimental conditions $[20,22]$. Therefore isolated human placental arteries and veins should be considered most suitable for in-vitro PE models.

In the present study our data suggest that cumulative $\mathrm{H}_{2} \mathrm{O}_{2}$ causes more potent vasoconstriction in endothelium denuded human umbilical arteries. This effect may be attributed to the loss of vasodilators produced by the endothelium such as NO, EDHF and $\mathrm{PGI}_{2}$. Similar results have been shown previously in the rat aorta $[17,22]$. Rodriguez-Martinez et al. [17] have demonstrated that oxygen-derived free radicals are involved in the contractile effects of $\mathrm{H}_{2} \mathrm{O}_{2}$; endothelium protects against oxidative injury caused by $\mathrm{H}_{2} \mathrm{O}_{2}$ in smooth muscle cells, endothelial NO has a protective role on the contractile effect induced by $\mathrm{H}_{2} \mathrm{O}_{2}$ in normotensive rats; and this protective role of endothelial NO is lost under oxidative stress such as hypertension. The role of ROS and NO in the pathogenesis of pre-eclampsia using human umbilical vein endothelial cell cultures, have been investigated by Matsubara et al. [9] in normal and pre-eclampsia patients. They argued that endothelial dysfunction during PE possibly results from the inactivation of NO by superoxide ions. This is supported by our results, in which umbilical artery strips incubated with L-NAME, which is a NO synthase inhibitor, significantly increased the contraction elicited by $\mathrm{H}_{2} \mathrm{O}_{2}$. Furthermore, complete endothelial removal resulted in higher vasoconstriction than the LNAME incubated human umbilical arteries. This implies that besides NO, other endothelial factors such as EDHF and PGI2 may be involved in the process. Together with previous literature, these results lead us to think that NO 
acts as a negative modulator against $\mathrm{H}_{2} \mathrm{O}_{2}$ elicited contractions in placental arteries and also may be protective against oxidative insult $[17,19,22]$.

Lelung et al. [3] have demonstrated that sodium nitroprusside, an exogenous source of NO, only elicits small significant relaxations in isolated human umbilical arteries. They are in the opinion that NO might not be the major mediator responsible for vasodilation in umbilical arteries. Previous work also suggests that, instead of NO prostacyclin was the main factor mediating the endothelium dependent relaxation in human umbilical arteries $[10,14,23]$. Klockenbush et al. [24] have suggested that rather than $\mathrm{NO}$, prostacyclin plays a major role in the vasoreactivity of umbilical and fetal circulation. $\mathrm{H}_{2} \mathrm{O}_{2}$ elicited vasoreactivity can be relaxation or constriction depending on the basal tonus of isolated pulmonary arteries, and these effects are mediated by phospholipase A2 activation leading to prostacyclin or thromboxane A2 release [25]. In the present study the $\mathrm{H}_{2} \mathrm{O}_{2}$ elicited contraction in umbilical arteries were significantly inhibited in the presence of indomethacin, a cyclooxygenase enzyme inhibitor. These data suggest that increased constrictor cyclooxygenase metabolites as a result of increased arachidonic acid metabolism partially mediate the constrictive effects of $\mathrm{H}_{2} \mathrm{O}_{2}$ in the vascular smooth muscle of human umbilical arteries. Previous research shows that prostaglandin $\mathrm{H} 2$ and more possibly thromboxane A2 are involved in the contractile response [26, 27]. These findings are in accordance with studies which, showed that $\mathrm{H}_{2} \mathrm{O}_{2}$ increases prostaglandin $\mathrm{F} 2 \alpha$ and thromboxane $\mathrm{A} 2$ in rat aorta smooth muscle $[28,29]$.

$\mathrm{Ca}^{2+}$ is essential for the contraction of smooth muscles and it is believed that intracellular $\mathrm{Ca}^{2+}$ homeostasis plays a major role in antioxidant activity [30-33]. The harmful effects of ROS can influence the ion channels or ion pumps, which maintain low $\mathrm{Ca}^{2+}$ levels under normal conditions [33,34]. It is known from previous work that in different tissues $\mathrm{H}_{2} \mathrm{O}_{2}$ can increase intracellular $\mathrm{Ca}^{2+}$ by promoting mobilization of $\mathrm{Ca}^{2+}$ and $\mathrm{Ca}^{2+}$ influx $[31,33$, 34]. In isolated rat cardiomyocytes Gen et al. [33] have shown that $\mathrm{H}_{2} \mathrm{O}_{2}$ increases intracellular $\mathrm{Ca}^{2+}$ in a dose dependent manner. In our study we have found that $\mathrm{H}_{2} \mathrm{O}_{2}$ induced contractions increase in a dose dependent pattern when cumulative $\mathrm{Ca}^{2+}$ was added after a single bolus of $\mathrm{H}_{2} \mathrm{O}_{2}$ in human umbilical arteries.

It has been reported that $\mathrm{NO}$ modulates $\mathrm{Ca}^{2+}$-channel activity in vascular smooth muscle and induces relaxation [35]. Incubation with verapamil, a $\mathrm{Ca}^{2+}$-channel antagonist significantly decreased but did not totally block $\mathrm{H}_{2} \mathrm{O}_{2}$ induced contractions. Sotnikova [22] and Yang et al. [36] have reported similar results in rat aorta with calcium antagonists. In the present study, both incubation with verapamil and resting the arteries in $\mathrm{Ca}^{2+}$-free medium attenuated but did not prevent $\mathrm{H}_{2} \mathrm{O}_{2}$ induced contractions. These findings suggest that both intracellular and extracellular $\mathrm{Ca}^{2+}$ mediate these contractions. It has been suggested previously that the decrease caused by ROS on membrane resistance may depolarize the cells and thus activate voltage sensitive $\mathrm{Ca}^{2+}$ channels and lead to an increase in intracellular $\mathrm{Ca}^{2+}[31,32]$. Also, $\mathrm{Ca}^{2+}$ channel blockers are thought to be ineffective in blocking mobilization of $\mathrm{Ca}^{2+}$ from intracellular stores but effectively block the influx of extracellular $\mathrm{Ca}^{2+}$ via the $\mathrm{L}$ type $\mathrm{Ca}^{2+}$ channels [33].

\section{Conclusions}

In conclusion, in this in-vitro model for oxidative stress we have demonstrated that exposure to $\mathrm{H}_{2} \mathrm{O}_{2}$ causes concentration-dependent constriction in human umbilical arteries. Removal of the endothelium increased the $\mathrm{H}_{2} \mathrm{O}_{2}$ elicited contractions more than incubation with L-NAME suggesting beside $\mathrm{NO}$, other endothelial vasodilators are also involved in vascular tonus of the umbilical arteries. Inhibition of $\mathrm{H}_{2} \mathrm{O}_{2}$ elicited contractions with indomethacin suggests that increased constrictor cyclooxygenase metabolites partially mediate the constrictive effects of $\mathrm{H}_{2} \mathrm{O}_{2}$ in the vascular smooth muscle of human umbilical arteries. Incubation with verapamil, and $\mathrm{Ca}^{2+}$ free medium significantly decreased but did not totally block $\mathrm{H}_{2} \mathrm{O}_{2}$ induced contractions suggesting both intracellular and extracellular $\mathrm{Ca}^{2+}$ involvement in $\mathrm{H}_{2} \mathrm{O}_{2}$ elicited contractions.

\section{REFERENCES}

[1] T. Todros, A. Sciarrone, E. Piccoli, C. Guiot, P. Kaufmann and J. Kingdom, "Umbilical Doppler Waveforms and Placental Villous Angiogenesis in Pregnancies Complicated by Fetal Growth Restriction," Obstetrics \& Gynecology, Vol. 93, No. 4, 1999, pp. 499-503. doi:10.1016/S0029-7844(98)00440-2

[2] A. Fleischer, H. Schulman, G. Farmakides, L. Bracero, L. Grunfeld, B. Rochelson and M. Koenigsberg, "Uterine artery Doppler Velocimetry in Pregnant Women with Hypertension," American Journal of Obstetrics \& Gynecology, Vol. 154, No. 4, 1986, pp. 806-813.

[3] S. W. Leung, A. Quan, T. T. Lao and R. Y. Man, "Efficacy of Different Vasodilators on Human Umbilical Arterial Smooth Muscle under Normal and Reduced Oxygen Conditions," Early Human Development, Vol. 82, No. 7, 2006, pp. 457-462.

doi:10.1016/j.earlhumdev.2005.11.009

[4] T. A. Mills, M. Wareing, A. A. H. Shennan, L. Poston, P. N. Baker and S. L. Greenwood, "Acute and Chronic Modulation of Placental Chorionic Plate Artery Reactivity by Reactive Oxygen Species," Free Radical Biology \& Medicine, Vol. 47, No. 2, 2009, pp. 159-166. 
doi:10.1016/j.freeradbiomed.2009.04.019

[5] N. Rani, R. Dhingra, D. S. Arya, M. Kalaivani, N. Bhatla and R. Kumar, "Role of Oxidative Stress Markers and Antioxidants in the Placenta of Preeclamptic Patients," Journal of Obstetrics and Gynaecology Research, Vol. 36, No. 6, 2010, pp. 1189-1194. doi:10.1111/j.1447-0756.2010.01303.x

[6] A. Cinkaya, H. L. Keskin, U. Buyukkagnici, T. Gungor, E. A. Keskin, A. F. Avsar and U. Bilge, "Maternal Plasma Total Antioxidant Status in Preterm Labor," Journal of Obstetrics and Gynaecology Research, Vol. 36, No. 6, 2010, pp. 1185-1188. doi:10.1111/j.1447-0756.2010.01300.x

[7] A. Negre-Salvayre, N. Auge, V. Ayala, H. Basaga, J. Boada, R. Brenke, S. Chapple, G. Cohen, J. Feher, T. Grune, G. Lengyel, G. E. Mann, R. Pamplona, G. Poli, M. Portero-Otin, Y. Riahi, R. Salvayre, S. Sasson, J. Serrano, O. Shamni, W. Siems, R. C. Siow, I. Wiswedel, K. Zarkovic and N. Zarkovic, "Pathological Aspects of Lipid Peroxidation," Free Radical Research, Vol. 44, No. 10, 2010, pp. 1125-1171. doi:10.3109/10715762.2010.498478

[8] T. Grune, N. Zarkovic and K. Kalliopi, "Lipid Peroxidation Sesearch in Europe and the COST B35 Action 'Lipid Peroxidation Associated Disorders'," Free Radical Research, Vol. 44, No. 10, 2010, pp. 1095-1097. doi:10.3109/10715762.2010.504395

[9] K. Matsubara, Y. Matsubara, S. Hyodo, T. Katayama and M. Ito, "Role of Nitric Oxide and Reactive Oxygen Species in the Pathogenesis of Preeclampsia," Journal of $\mathrm{Ob}$ stetrics and Gynaecology Research, Vol. 36, No. 2, 2010, pp. 239-247. doi:10.1111/j.1447-0756.2009.01128.x

[10] L. Carbillon, M. Uzan and S.Uzan, "Pregnancy, Vascular Tone, and Maternal Hemodynamics: A Crucial Adaptation," Obstetrical \& Gynecological Survey, Vol. 55, No. 9, 2000, pp. 574-581. doi:10.1097/00006254-200009000-00023

[11] T. Matoba and H. Shimokawa, "Hydrogen Peroxide Is an Endothelium-Derived Hyperpolarizing Factor in Animals and Humans," Journal of Pharmacological Sciences, 2003, Vol. 92, No. 1, pp. 1-6. doi:10.1254/jphs.92.1

[12] K. Rytlewski, H. Huras, K. Kusmierska, A. Jaworowski, T. Gornisiewicz, P. Ossowski and A. Reron, "Doppler Velocimetry of the Materno-Fetal Circulation in Preterm Delivered Pregnancies Complicated with Hypertension," Neuroendocrinology Letters, Vol. 30, No. 3, 2009, pp. 403-408.

[13] R. Cruz-Martinez and F. Figueras, "The Role of Doppler and Placental Screening," Best Practice \& Research Clinical Obstetrics \& Gynaecology, Vol. 23, No. 6, 2009, pp. 845-855. doi:10.1016/j.bpobgyn.2009.08.007

[14] Y. Okatani, K. Watanabe and Y. Sagara, "Effect of Nitric Oxide, Prostacyclin and Tromboxane on the Vasospastic Action of Hydrogen Peroxide on Human Umbilical Artery," Acta Obstetricia et Gynecologica Scandinavica, Vol. 76, No. 6, 1997, pp. 515-520.

[15] Y. Okatani, K. Watanabe, A. Wakatsuki, S. Tamura and
Y. Sagara, "Effects of Superoxide and Peroxynitrite on Vascular Tension in the Human Umbilical Artery," Acta Obstetricia et Gynecologica Scandinavica, Vol. 77, No. 9, 1998, pp. 883-888. doi:10.1080/j.1600-0412.1998.770902.x

[16] N. Jin, C. S. Packer and R. A. Rhoades, "Reactive Oxygen-Mediated Contraction in Pulmonary Arterial Smooth Muscle: Cellular Mechanisms," Canadian Journal of Physiology and Pharmacology, Vol. 69, No. 3, 1991, pp. 383-388. doi: 10.1139/y91-058

[17] M. A. Rodríguez-Martínez, E. C. García-Cohen, A. B. Baena, R. González, M. Salaíces and J. Marín, "Contractile Responses Elicited by Hydrogen Peroxide in Aorta From Normotensive and Hypertensive Rats. Endothelial Modulation and Mechanism Involved," British Journal of Pharmacology, Vol. 125, No. 6, 1998, pp. 1329-1335. doi:10.1038/sj.bjp.0702200

[18] T. Hattori, J. Kajikuri, H. Katsuya and T. Itoh, "Effects of $\mathrm{H}_{2} \mathrm{O}_{2}$ on Membrane Potential of Smooth Muscle Cells in Rabbit Mesenteric Resistance Artery," European Journal of Pharmacology, Vol. 464, No. 2-3, 2003, pp. 101-109. doi:10.1016/S0014-2999(03)01427-4

[19] Y. J. Gao, S. Hirota, D. W. Zhang, L. J. Janssen and R. M. Lee, "Mechanisms of Hydrogen-Peroxide-Induced Biphasic Response in Rat Mesenteric Artery," British Journal of Pharmacology, Vol. 138, No. 6, 2003, pp. 1085-1092.

[20] S. Fujimoto, M. Mori and H. Tsushima, "Mechanisms Underlying the Hydrogen Peroxide-Induced, EndotheliumIndependent Relaxation of the Norepinephrine-Contraction in Guinea-Pig Aorta," European Journal of Pharmacology, Vol. 459, No. 1, 2003, pp. 65-73. doi:10.1016/S0014-2999(02)02825-X

[21] R. S. Barlow and R. E. White, "Hydrogen Peroxide Relaxes Porcine Coronary Arteries by Stimulating BKCa Channel Activity," American Journal of Physiology: Heart and Circulatory Physiology, Vol. 275, No. 4, 1998, pp. H1283H1289.

[22] R. Sotnikova, "Investigation of the Mechanisms Underlying $\mathrm{H}_{2} \mathrm{O}_{2}$-Evoked Contraction in the Isolated Rat Aorta," General Pharmacology, Vol. 31, No. 1, 1998, pp. 115-119. doi:10.1016/S0306-3623(97)00392-3

[23] G. Bodelsson and M. Stjernquist, "Endothelium-Dependent Relaxation to Substance P in Human Umbilical Artery Is Mediated via Prostanoid Synthesis," Human Reproduction, Vol. 9, No. 4, 1994, pp. 733-737.

[24] W. Klockenbusch, H. Strobach and K. Schrör, "Any Physiological Role for Prostacyclin in Regulation of Fetal Vessel Tone?" Agents \& Actions, Vol. 37, No. 1, 1992, pp. 361-368.

[25] D. W. Sheehan, E. C. Giese, S. F. Gugino, J. A. Russell, "Characterization and Mechanisms of $\mathrm{H}_{2} \mathrm{O}_{2}$-Induced Contractions of Pulmonary Arteries," American Journal of Physiology: Heart and Circulatory Physiology, Vol. 264, No. 5, 1993, pp. H1542-H1547.

[26] K. Watanabe, Y. Okatani and Y. Sagara, "Potentiating Effect of Hydrogen Peroxide on the Serotonin-Induced Vasocontraction in Human Umbilical Artery," Acta $\mathrm{Ob}$ - 
stetricia et Gynecologica Scandinavica, Vol. 75, No. 9, 1996, pp. 783-789. doi:10.3109/00016349609054704

[27] M. S. Wolin, C. A. Davidson, P. M. Kaminski, R. P. Fayngersh and K. M. Mohazzab-H., "Oxidant-Nitric Oxide Signalling Mechanisms in Vascular Tissue," Biochemistry (Moscow), Vol. 63, No. 7, 1998, pp. 810-816.

[28] S. López-Ongil, G. Torrecillas, D. Pérez-Sala, L. GonzálezSantiago, M. Rodríguez-Puyol and D. Rodríguez-Puyol, "Mechanisms Involved in the Contraction of Endothelial Cells by Hydrogen Peroxide," Free Radical Biology \& Medicine, Vol. 26, No. 5-6, 1999, pp. 501-510. doi:10.1016/S0891-5849(98)00223-8

[29] P. Srivastava, M. Rajanikanth, S. A. V. Raghavan and M. Dikshit, "Role of Endogenous Reactive Oxygen Derived Species and Cyclooxygenages Mediators in 5-Hydroxytryptamine-Induced Contractions in Rat Aorta: Relationship to Nitric Oxide," Pharmacological Research, Vol. 45, No. 5, 2002, pp. 375-382. doi:10.1006/phrs.2001.0859

[30] J. Daut, N. B. Standen and M. T. Nelson, "The Role of Membrane Potential of Endothelial and Smooth Muscle Cells in the Regulation of Coronary Blood Flow," Journal of Cardiovascular Electrophysiology, Vol. 5, No. 2, 1994, pp. 154-181. doi:10.1111/j.1540-8167.1994.tb01156.x

[31] K. Bielefeldt, C. A. Whiteis, R. V. Sharma, F. M. Abboud and J. L. Conklin, "Reactive Oxygen Species and Calcium Homeostasis in Cultured Human Intestinal Smooth Muscle Cells," American Journal of Physiology: Heart and Circulatory Physiology, Vol. 272, No. 6, 1997, pp. G1439-G1450.

[32] A. Roveri, M. Coassin, M. Maiorino, A. Zamburlini, F. T. van Amsterdam, E. Ratti and F. Ursini, "Effect of Hydrogen Peroxide on Calcium Homeostasis in Smooth Muscle Cells," Archives of Biochemistry and Biophysics, Vol. 297, No. 2, 1992, pp. 265-270. doi:10.1016/0003-9861(92)90671-I

[33] W. Gen, M. Tani, J. Takeshita J, Y. Ebihara and K. Tamaki, "Mechanisms of $\mathrm{Ca}^{2+}$ Overload Induced by Extracellular $\mathrm{H}_{2} \mathrm{O}_{2}$ in Quiescent Isolated Rat Myocytes," Basic Research in Cardiology, Vol. 96, No. 6, 2001, pp. 623-629. doi:10.1007/s003950170014

[34] J. Tang and J. H. Zhang, "Mechanisms of $\left(\mathrm{Ca}^{2+}\right)_{\mathrm{i}}$ Elevation by $\mathrm{H}_{2} \mathrm{O}_{2}$ in Islets of Rats," Life Sciences, Vol. 68, No. 4, 2000, pp. 475-481. doi:10.1016/S0024-3205(00)00944-9

[35] L. A. Blatter and W. G. Wier, "Nitric Oxide Decreased $\left[\mathrm{Ca}^{2+}\right] \mathrm{i}$ in Vascular Smooth Muscle by Inhibition of the Calcium Current," Cell Calcium, Vol. 15, No. 2, 1994, pp. 122-131. doi:10.1016/0143-4160(94)90051-5

[36] D. Yang, M. Feletou, C. M. Boulanger, H. F. Wu, N. Levens, J. N. Zhang and P. M. Vanhoutte, "Oxygen-Derived Free Radicals Mediate Endothelium-Dependent Contractions to Acetylcholine in Aortas from Spontaneously Hypertensive Rats," British Journal of Pharmacology, Vol. 136, No. 1, 2002, pp. 104-110. doi:10.1038/sj.bjp.0704669 